\title{
r.hu-Erythropoietin (EPO) treatment of pre-ESRD patients slows the rate of progression of renal decline Mihály Tapolyai ${ }^{*+1}$, Satoshi Kadomatsu ${ }^{\dagger 1}$ and Manuel Perera-Chong 2
}

\author{
Address: ${ }^{1}$ Department of Nephrology and Hypertension, Cleveland Clinic Florida, USA and ${ }^{2}$ Clinical Management Europe, Fresenius Medical \\ Care, USA \\ Email: Mihály Tapolyai* - MTapolyai@aol.com; Satoshi Kadomatsu - unagi31042002@yahoo.com; Manuel Perera-Chong - Manuel.Perera- \\ Chang@fmc-ag.com \\ * Corresponding author †Equal contributors
}

Published: 17 June 2003

BMC Nephrology 2003, 4:3
Received: 12 December 2002

Accepted: 17 June 2003

This article is available from: http://www.biomedcentral.com/I47I-2369/4/3

(C) 2003 Tapolyai et al; licensee BioMed Central Ltd. This is an Open Access article: verbatim copying and redistribution of this article are permitted in all media for any purpose, provided this notice is preserved along with the article's original URL.

\begin{abstract}
Background: As EPO treatment of chronic anemia of advanced renal disease is now the standard of care we examined if such treatment may slow the progression of renal function decline.

Methods: Data of 18 pre-ESRD patients were analyzed retrospectively 12 months prior and prospectively 12 months after the initiation of EPO. Mean creatinine was $5.0 \pm 1.8 \mathrm{mg} / \mathrm{dL}$ (Mean \pm SEM) when starting EPO at a weekly dose of $5000 \pm 500$ units once the hematocrit was below 30 \%. EPO dose was titrated monthly for a hematocrit between $33.0 \%$ and $37.0 \%$. Metabolic complications and hypertension were controlled.

Results: At month_0 the average blood pressure was $148 / 76 \pm 5 / 4 \mathrm{mmHg}$ and at month_12 it was $145 / 73 \pm 6 / 3 \mathrm{mmHg}$ ( $P=0.75$ by 2 tailed paired Student's $t$ test). $12 / 18$ patients were on an ACEi or ARB before month_0 and I $4 / 18$ were on it after $(p=0.71$ by Fisher's 2 tailed exact test). The average hematocrit rose from $26.9 \% \pm 0.6$ to $33.1 \% \pm 0.1$. When linear regression analysis was applied to pre- and post-EPO I/creatinine data the mean rate of decline was $-0.0140 \pm 0.0119$ (mean $\pm S D$ ) and $-0.0017 \pm 0.0090$ (non-parametric Wilcoxon matched pairs signed rank sum test: $Z$ value: $-2.9 \mathrm{I} ; \mathrm{P}=0.004$ ) respectively. $5 / \mathrm{I} 8$ patients did not require dialysis $I 2$ months after starting EPO (month_0).
\end{abstract}

Conclusion: Treatment of the anemia of chronic renal failure with erythropoietin, when instituted together with vigorous metabolic control may slow the rate of renal function decline.

\section{Background}

Chronic renal failure is often a progressive rather than a stable process which most frequently leads to end stage renal disease (ESRD). There are very few maneuvers that can ameliorate the course of renal insufficiency such as the use of ACE-inhibitors, aggressive blood pressure control or vigorous glucose control. As the renal function progressively declines complications of renal failure such as acidosis, uremia or volume overload become more and more significant and eventually may be the principal reason for the initiation of renal replacement therapy. These complications of chronic renal failure, however, can be managed for awhile with medical therapy. We noted that the control of anemia of renal failure not only manages the complication of chronic renal failure but also slows the rate of renal function decline or in some cases it arrests the process. As the treatment of anemia of pre-ESRD patients with EPO is now the standard of care we 
investigeted whether such treatment may indeed slow the progression of renal function decline.

\section{Methods}

\section{Study design}

This is a prospective, observational-clinical cohort study of patients treated for cohort anemia. Data were analyzed to compare the rate of progression of renal disease based on serum creatinine values before the initiation of human recombinant erythropoietin (EPO) [Procrit ${ }^{\circledast}$ by Ortho Biotech] and after.

\section{Inclusion criteria}

Adult patients who developed a renal disease who progressed to the stage requiring treatment of their anemia by subcutaneous EPO. Patients had to have at least three months' data prior to the EPO therapy followed by at least three months' data after therapy was started in our outpatient nephrology clinic at a tertiary referral center. Data of patients of any renal disease with a severe renal failure were examined including glomerulonephritides, lupus nephritis, diabetic nephropathy and unknown renal diseases.

\section{Exclusion criteria}

Transplant recipient status, acute renal failure or anemia identified as other than secondary to chronic renal failure were exclusion criteria.

\section{Methods}

Patients with severe renal failure were identified at the time of initiating EPO treatment in a clinical setting. Data of 35 such patients were examined and 18 qualified for data analysis. Data were analyzed in a retrospective manner 1 year prior and prospectively one year after the initiation of EPO. The mean age of patients was $67.3 \pm 0.05$ (Mean \pm SEM) years at the start of the observation, 2 were African Americans and one was Hispanic, 6 patients were women and 7 had type II diabetes mellitus. The exact pathology for the renal failure was not known in the majority of patients, but one was known to have polycystic kidney disease. The patients' mean creatinine was $5.0 \pm 1.8 \mathrm{mg} / \mathrm{dL}$ at the time of starting subcutaneous EPO at a starting weekly dose of $5000 \pm 500$ units depending on the degree of anemia when the patient's hematocrit was less than $30 \mathrm{mg} \%$. EPO dose was adjusted monthly to keep the hematocrit between $33.0 \%$ and $37.0 \%$. All patients were monitored with monthly physical examination as well as laboratory tests that included hemoglobin, hematocrit, iron saturation, Blood Urea Nitrogen, creatinine and electrolytes. Iron was supplemented by oral iron preparations described to be taken daily but when the iron saturation reached less than $20 \%$ then intravenous iron dextran was given in an outpatient setting in divided doses to reach $1 \mathrm{gm}$ per course. Metabolic acidosis was controlled to keep the "CO2" (bicarbonate) on the electrolyte panel greater than $22 \mathrm{mmol} / \mathrm{L}$ by either oral sodium bicarbonate or sodium citrate. Potassium was primarily controlled by controlling the metabolic acidosis, diuretics or occasionally by oral sodium polystyrene. Blood pressure control was maximized with a preference for an angiotensin converting enzyme inhibitor (ACE-i) or angiotensin receptor blocking agent (ARB). A nephrologist saw all patients monthly.

\section{End points}

Patients were monitored and their data collected until they required dialysis or death (there was none) or lost to follow up $(1 / 18)$ whose data were censored. Necessity for dialysis was decided when patients started to have uremic symptoms or metabolic complications that could no longer be managed medically.

\section{Results}

5 of the 18 patients did not require dialysis at the end of the 12 months period after starting EPO (month_0). At month 0 the average blood pressure was $148 / 76 \pm 5 / 4$ (mean \pm SEM) $\mathrm{mmHg}$ and at month_12 the mean blood pressure was $145 / 73 \pm 6 / 3 \mathrm{mmHg}(\mathrm{p}=0.75$ by 2 tailed paired Student's t test). 12/18 patients were on an ACE-i or ARB before month 0 and $14 / 18$ were on it after $(\mathrm{p}=$ 0.71 by Fisher's 2 tailed exact test). After starting EPO the average hematocrit rose from $26.9 \pm 0.6$ to $33.1 \pm 0.1$ where they were maintained. When linear regression analysis was applied to pre- and post-EPO 1/creatinine data the mean rate of $1 /$ creatinine decline was $-0.0140 \pm$ 0.0119 (mean \pm SD) and $-0.0017 \pm 0.0090$ (using the non-parametric Wilcoxon matched pairs signed rank sum test: $Z$ statistical value of -2.91 which corresponds to a two tailed $P=0.004)$ respectively. The slope of the creatinine rise changed to a negative value in 6 of the 18 patients' case with this treatment indicating actual reversal.

\section{Discussion}

Although treatment the anemic complication of renal failure has been available since the late 1980's when EPO became available treatment of it was delayed perhaps because of initial concerns that EPO treatment may actually worsen the progression of renal disease. This suspicion was based on rat studies that indicated that perhaps anemia has a nephro-protective effect and the correction of it would accelerate renal injury $[1,2]$. However, in a double-blind placebo-controlled clinical trial there was no adverse renal effect demonstrated over a 12-week period [3] as expressed by $1 /$ creatinine versus time. Similarly, in a 24-week prospective open-label study the rate of decline in kidney function was not altered by the use of EPO [4]. We also used 1/creatinine values as the index of renal function instead of creatinine because of the linear 


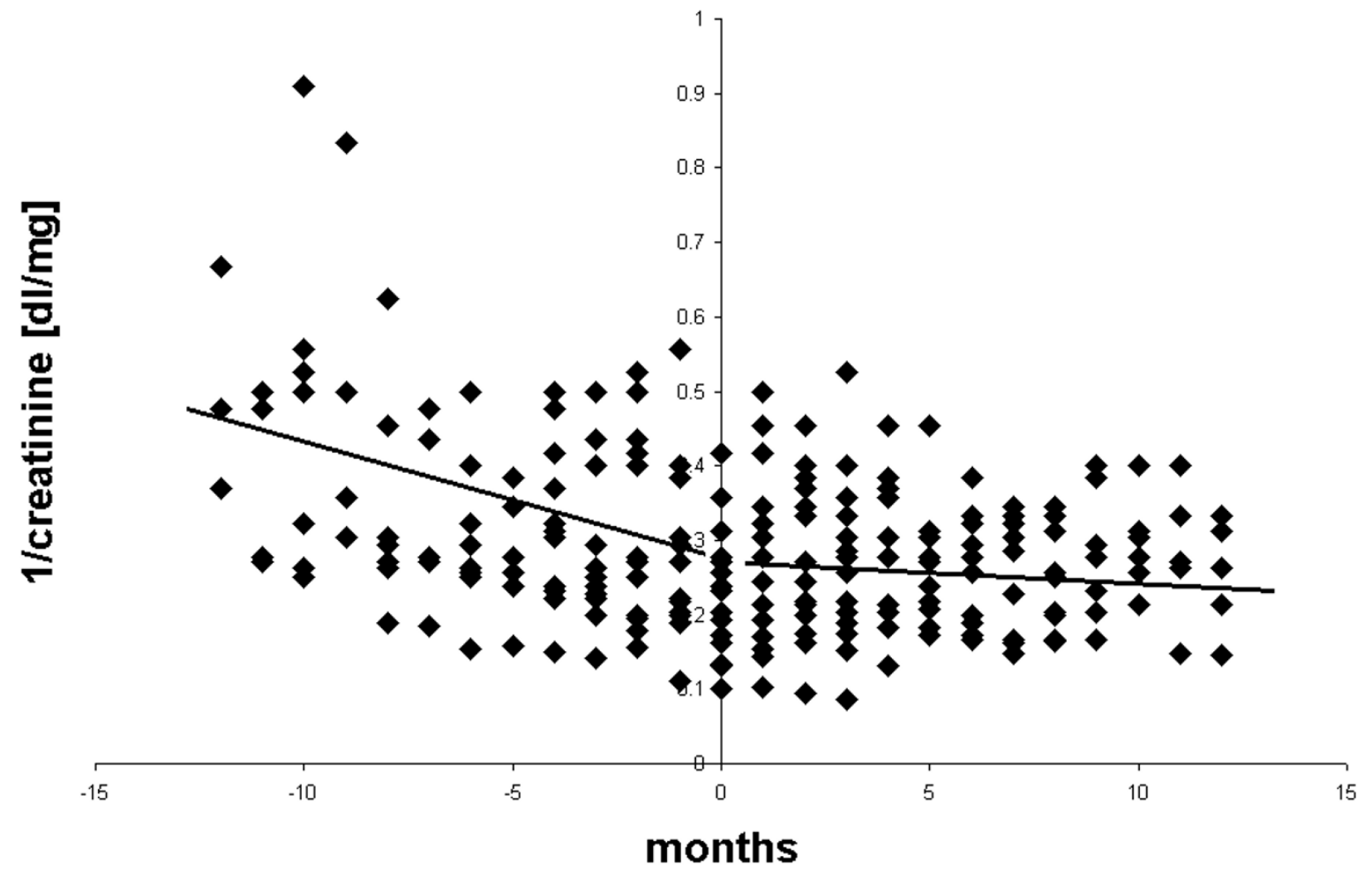

Figure I

I/creatinine values before and after EPO treatment. The rate of progression of renal function decline as reflected by the linear regression lines slowed from $-0.0140 \mathrm{dL} / \mathrm{mg} \cdot \mathrm{month} \pm 0.0119$ (mean $\pm \mathrm{SD}$ ) to $-0.0017 \mathrm{dL} / \mathrm{mg} \cdot \mathrm{month} \pm 0.0090$ (nonparametric Wilcoxon matched pairs signed rank sum test: $Z$ statistical value of -2.91 which corresponds to a two tailed $P=$ 0.004) after starting EPO at Month 0.

correlation of $1 /$ creatinine with the glomerular filtration rate as opposed to the pure creatinine values $[5,6]$.

Lim at al. [7] who also compared the slopes of linear regression lines of the renal function of 26 patients over 24 months found that neither EPO administration nor a normal hematocrit had any adverse effect on the renal function. Others [8] have also confirmed that normalization of the hematocrit with EPO does not accelerate the loss of the residual renal function.

Our findings indicate that the treatment of anemia of chronic renal failure may prolong the renal survival. This is consistent with others' findings. A pediatric study from Germany by Krmar et al.[9] as well as by Kuriyama [10] who compared treated and untreated patients had similar results. When compared, the treated patients had a lower rate of progression of the renal decline in both studies albeit the number of patients in the pediatric study was 11 thus no statistical significance could be shown.

Recently, Jungers [11] also found that the rate of progression of renal failure is slower in patients who receive EPO than those who do not with a delayed need for initiation of dialysis.

The possibility of explanations is rather wide. One could speculate better oxygen delivery to the ischemic tissues may be responsible for this beneficial effect. This process would lower the ischemic burden perhaps by beneficial effects of EPO on endothelial dysfunction as evidenced by thrombomodulin/ creatinine ratios when treated with 
EPO [12]. Other mechanism could involve the suppression of hormones such as angiotensin and aldosterone, both of which are known to have important roles in tissue damage and fibrosis. Since captopril was shown [13] to increase the effective renal plasma flow and renal blood flow in anemic pre-dialysis patients and this effect could no longer be observed when treated with EPO it is possible that the correction of anemia may involve these hormones that act of the efferent arterial resistance or other hemodynamic modulators. Other fibrosis promoting participant substances could also include TGF-beta yet their role and response to EPO remains to be shown. While this is only an observational study from the clinical practice with a relatively small number of patients it could point towards the necessity for a larger prospective study designed to answer the question raised here whether the administration of EPO in the pre-ESRD population can indeed reverse or halt a process of continuous renal decline.

\section{Conclusions}

Treatment of the anemia of chronic renal failure with subcutaneous erythropoietin, when instituted together with the vigorous control of the metabolic complications of chronic renal failure may slow the rate of renal function decline and in some cases may even reverse the process of renal function loss.

\section{Competing interests}

As part of our full disclosure statement we declare that we had no financial or any other interest nor did we have any external support for this study.

\section{Authors' contributions}

MT conceived of and collected the data and compiled wrote the study.

SK had a major share in evaluating and interpreting the data as well as writing the manuscript.

MPC is a mathematician and statistician who performed the appropriate calculations and statistical analysis.

\section{References}

I. Lafferty HM, Garcia DL, Rennke HG, Troy JL, Anderson S and Brenner BM: Anemia ameliorates progressive renal injury in experimental DOCA-salt hypertension J Am Soc Nephrol I99।, I(I0): I I80-5

2. Garcia DL, Anderson S, Rennke HG and Brenner BM: Anemia lessens and its prevention with recombinant human erythropoietin worsens glomerular injury and hypertension in rats with reduced renal mass Proc Natl Acad Sci U S A 1 988, 85(16):6 I42-6.

3. Kleinman KS, Schweitzer SU, Perdue ST, Bleifer KH and Abels RI: The use of recombinant human erythropoietin in the correction of anemia in predialysis patients and its effect on renal function: a double-blind, placebo-controlled trial Am J Kidney Dis 1989, 14(6):486-95.

4. Yagil Y: Proposed therapeutic algorithm for the treatment of anemia of chronic renal failure in pre-dialysis patients with low dose once weekly subcutaneous r-HuEPO. Multicenter Study Group, Israel Isr J Med Sci 1997, 33(I):36-44.

5. Rutherford WE, Blondin J, Miller JP, Greenwalt AS and Vavra JD: Chronic progressive renal disease: Rate change of serum creatinine concentration Kidney Int 1977, I I:62-70.

6. Mitch WE, Walser M, Buffington GA and Lemann J: A simple method of estimating progression of chronic renal failure Lancet 1976, 18:1326-1328.

7. Lim VS, Fangman J, Flanigan MJ, DeGowin RL and Abels RT: Effect of recombinant human erythropoietin on renal function in humans Kidney Int 1990, 37(I): I3I-6.

8. Roth D, Smith RD, Schulman G, Steinman TI, Hatch FE, Rudnick MR, Sloand JA, Freedman BI, Williams WW Jr and Shadur CA: Effects of recombinant human erythropoietin on renal function in chronic renal failure predialysis patients Am J Kidney Dis 1994, 24(5):777-84.

9. Krmar RT, Gretz N, Klare B, Wuhl E and Scharer K: Renal function in predialysis children with chronic renal failure treated with erythropoietin Pediatr Nephrol 1997, I I (1):69-73.

10. Kuriyama S, Tomonari $\mathrm{H}$, Yoshida $\mathrm{H}$, Hashimoto $\mathrm{T}$, Kawaguchi $\mathrm{Y}$ and Sakai O: Reversal of anemia by erythropoietin therapy retards the progression of chronic renal failure, especially in nondiabetic patients Nephron 1997, 77(2): 176-85.

II. Jungers P, Choukroun G, Oualim A, Robino C, Nguyen AT and Man NK: Beneficial influence of recombinant human erythropoietin therapy on the rate of progression of chronic renal failure in predialysis patients Nephrol Dial Transplant 200I, 16:307-3I2.

12. Kuriyama S, Hopp L, Yoshida H, Hikita M, Tomonari H, Hashimoto T and Sakai O: Evidence for amelioration of endothelial cell dysfunction by erythropoietin therapy in predialysis patients $\mathrm{Am}$ J Hypertens 1996, 9(5):426-3I.

13. Frenken LA, Wetzels JF, Sluiter HE and Koene RA: Evidence for renal vasodilation in pre-dialysis patients during correction of anemia by erythropoietin Kidney Int 1992, 4 I (2):384-7.

\section{Pre-publication history}

The pre-publication history for this paper can be accessed here:

http://www.biomedcentral.com/1471-2369/4/3/prepub

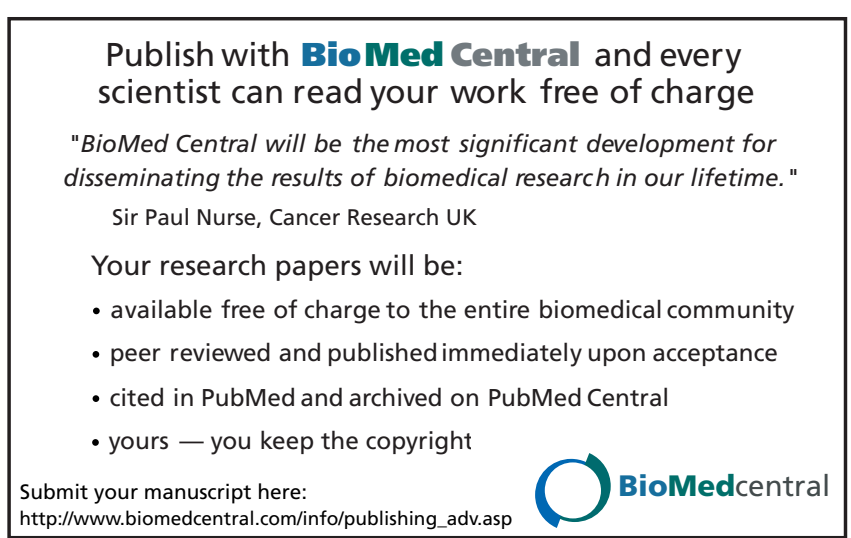

